\title{
Food access initiatives: An integral piece of the Revere, Massachusetts, COVID-19 response
}

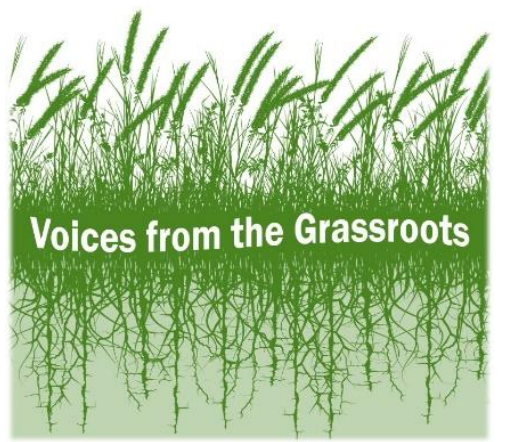

\author{
Molly Babbin a, b \\ Cambridge Health Alliance and Middlebury College
}

Rachel M. Zack ${ }^{\mathrm{c}}$

The Greater Boston Food Bank

Jean Granick $\mathrm{d}^{*}$ and Kathleen Betts e

Cambridge Health Alliance

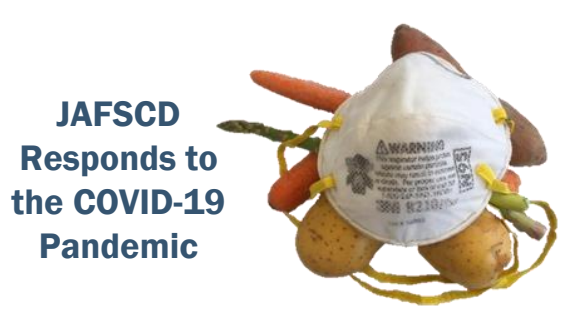

Submitted October 1, 2020 / Published online February 3, 2021

Citation: Babbin, M., Zack, R. M., Granick, J., \& Betts, K. (2021). Food access initiatives: An

integral piece of the Revere, Massachusetts, COVID-19 response. Journal of Agriculture, Food Systems,

and Community Development, 10(2), 313-318. https://doi.org/10.5304/jafscd.2021.102.017

Copyright (C) 2021 by the Authors. Published by the Lyson Center for Civic Agriculture and Food Systems. Open access under CC-BY license.

\section{Introduction}

Cambridge Health Alliance (CHA) is a community health care system that serves the region north of Boston, including the city of Revere, Massachusetts. In an effort to confront the root causes of poor health, CHA has engaged in an initiative to address the social determinants of health, including food insecurity, homelessness, and unemployment. In 2017 , we learned that $51 \%$ of our patients in Revere screened positive for food insecurity. In response, we committed to increasing our patients' access to healthy foods.

a Molly Babbin, Intern, Community Health Improvement Department, Cambridge Health Alliance;

mbabbin@,challiance.org

b Molly Babbin, BA Candidate, Middlebury College; 14 Old Chapel Road; Middlebury, VT 05753 USA.

c Rachel M. Zack, ScD, ScM, Senior Data Analyst, The Greater Boston Food Bank; 70 South Bay Avenue; Boston, MA 02118 USA; rzack@gbfb.org
Unfortunately, the COVID-19 pandemic has exacerbated Revere's existing financial and health challenges: unemployment spiked, and during several periods of the past seven months, the city experienced the second-highest infection rate in Massachusetts. To support the community, we worked with The Greater Boston Food Bank (GBFB) to expand our monthly free produce

$\mathrm{d} *$ Corresponding author: Jean Granick, MS, Community Health Improvement Department, Cambridge Health Alliance; 1035 Cambridge Street, Suite 23; Cambridge, MA 02141 USA; +1-617-806-8775; jgranick@,challiance.org

e Kathleen Betts, MPH, Community Health Improvement Department, Cambridge Health Alliance; kbetts@,challiance.org

\section{Acknowledgments}

We would like to thank Charlie Giuffrida, Dimple Rana, and Ralph Decicco for sharing their knowledge about and experiences in Revere's pandemic response. We are also appreciative of Kim Hanton's guidance and feedback. 
market at our local health center. We also joined forces with city leadership to promote the produce market, organize food truck pop-ups, and support the city's rapid expansion of innovative and coordinated food distribution programs. Figure 1 illustrates the components of Revere's food response.

Ultimately, the true heroes of Revere's COVID-19 food mobilization were city leaders Charlie Giuffrida, assistant director of Parks \&
Recreation; Dimple Rana, director of Outreach and Healthy Community Initiatives; and Ralph

Decicco, volunteer coordinator and chair of the Revere Commission on Disabilities. We spoke with them, as well as with Dr. Rachel Zack, senior data analyst at GBFB, and Jean Granick, community health improvement manager and Revere Mobile Market director at CHA, to highlight the key components and best practices of Revere's community food assistance response to COVID-19.

\section{Figure 1. The Community Food Response to COVID-19 in Revere, Massachusetts}

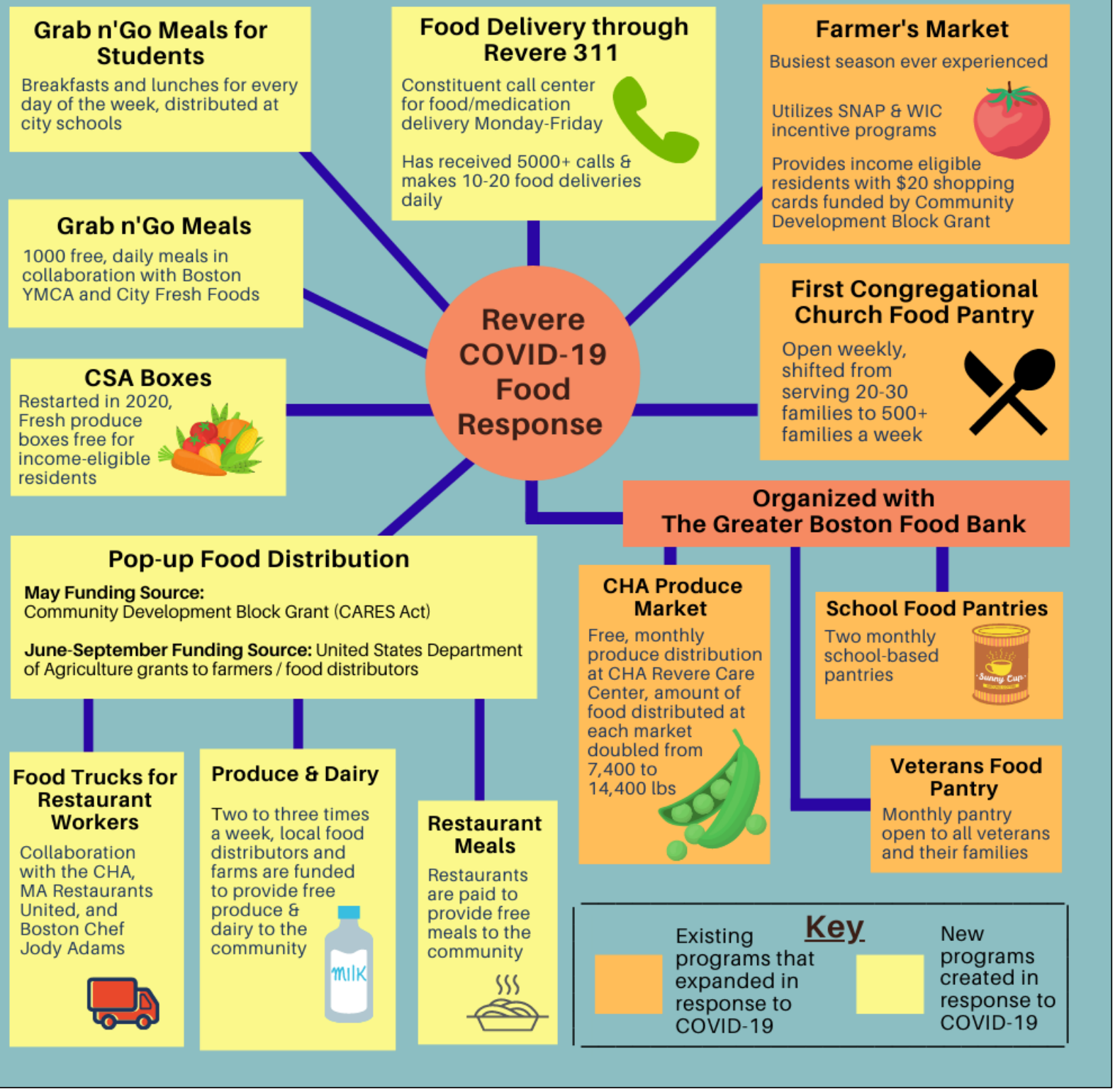


The following interview has been edited for brevity and clarity.

Molly Babbin: What were the most important steps to building a coordinated food response in Revere?

Charlie Giuffrida: One of the first things we did was assemble a team. We agreed immediately that we needed to repurpose city staff. For example, I'm the assistant director of Parks and Recreation. However, I'm not doing Parks and Recreation anymore because they repurposed me for food distribution.

Dimple Rana: We worked on finding a central food distribution center. We decided to use a public middle school to house the food pantry, the delivery system, the pop-ups, and our grab 'n' go program.
Charlie: The food pantry in Revere already had the infrastructure to provide food. We helped them move from their 30+-year church location to the school. We developed a delivery system around that food pantry for people who were in quarantine, mobility challenged, or just scared to leave their home. We found out about their needs using Revere 311, which is our way to directly interact with constituents. We have conversations with residents, listen to what they're dealing with, and connect them to the services they need. In the 10 minutes we've been on the phone, I have received four requests for help via 311.

Then we realized that when the government passed the CARES package, trillions of dollars were available. Our local businesses were suffering, so we created a pop-up program in May and paid local businesses to give us food. We distributed produce and dairy twice a week and had multiple food truck events. [See Figure 2.]

\section{Figure 2. Pop-up Food Truck Event with Meals from Several Boston Restaurants}

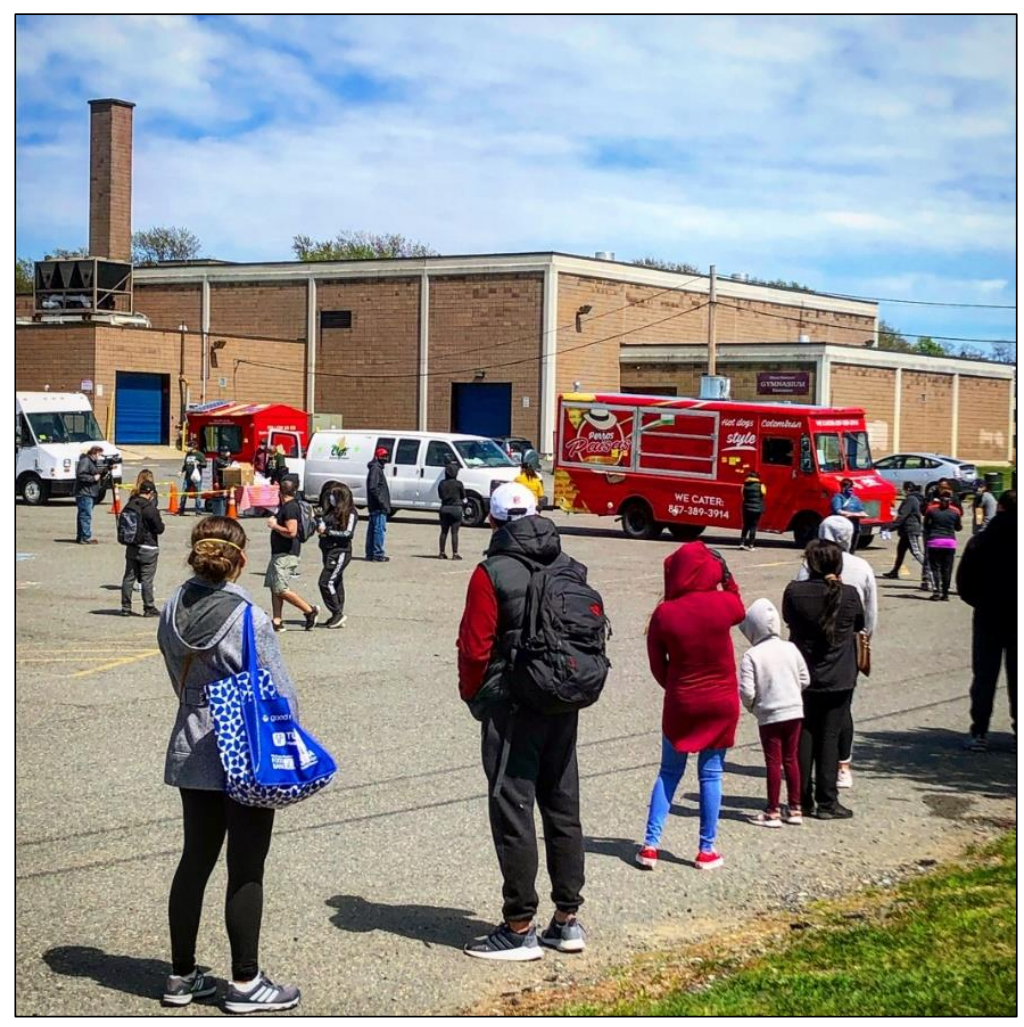

Photo by Jean Granick.
Dimple: After the CARES Act funding was gone, the USDA started another initiative and worked with farms directly to fund them. They enlisted farms and food rescue organizations to become the pop-up program distributors.

Charlie: So, because of the USDA funding, the pop-up program we had in May morphed into a situation where, all of a sudden, vendors started calling us saying, "Hey, I have to find a community partner. Can you be that person?"

Overall, we built a food distribution system composed of volunteers, existing infrastructure, repurposed city staff, CARES money, and local vendors. We did what we could for 60 days until the USDA arrived with reinforcements and allowed us to continue our programs throughout the summer.

Dimple: We also have a farmers market dedicated to serving low- 
income residents. We have incentive and federal programs that allow residents who qualify to shop at the market. This is the sixth season that we've run the farmers market, and this has been the busiest season ever. We also restarted our community supported agriculture (CSA) program. We had attempted it back in 2015, but it wasn't successful. Now, we're averaging 50 to 70 CSA produce boxes weekly, and we have Community Block Development Grant money to subsidize the cost for income-eligible residents.

Ralph Decicco: Without volunteers, we would not be able to run these programs. We had volunteers helping with delivery to the most vulnerable, and volunteers coming to the food pantry to help. At the beginning of the pandemic, we had an outpouring of volunteers. We had people from school departments, teachers, college students, and residents. [See Figure 3.]

Molly: How did CHA and GBFB adapt to support the community response in Revere?

Jean Granick: We knew our patients were in need of food, so we adapted our monthly produce market: we eliminated registration, added nonperishable items, recruited nonclinical staff as volunteers, and put measures in place to ensure social distancing. CHA's city and nonprofit partners helped promote the market, and we have reached over 650 households.

Dr. Rachel Zack: During the first six months of the COVID-19 pandemic, in order to support the increased demand for food assistance, GBFB more than doubled the amount of food distributed to Revere, from an average of 39,000 to 87,000 pounds a month. [See Figure 4.]

Molly: How did you get the word out to Revere residents?
Charlie: First, we made 15,000 phone calls to residents. We called seniors, families, and new moms. And we did a lot of grassroots stuff. The Parks and Recreation staff were in the parks almost every weekend all summer, handing out masks and passing along information about our food programs.

Our city also has a strong social media presence. Four city platforms were amplifying the food programs, especially to immigrant communities. We had the newspaper, Revere TV, and mailers to help reach our senior community. Everything we did said, "Call 311." We just stayed consistent on that message.

Next, we convened a committee of about 25 community Facebook page administrators to coordinate our social media messages around specific core issues. So, let's say we were going to talk about masks. In the Parks and Rec department, we

\section{Figure 3. Volunteers Bag Food for Revere's First Congregational Church Food Pantry}

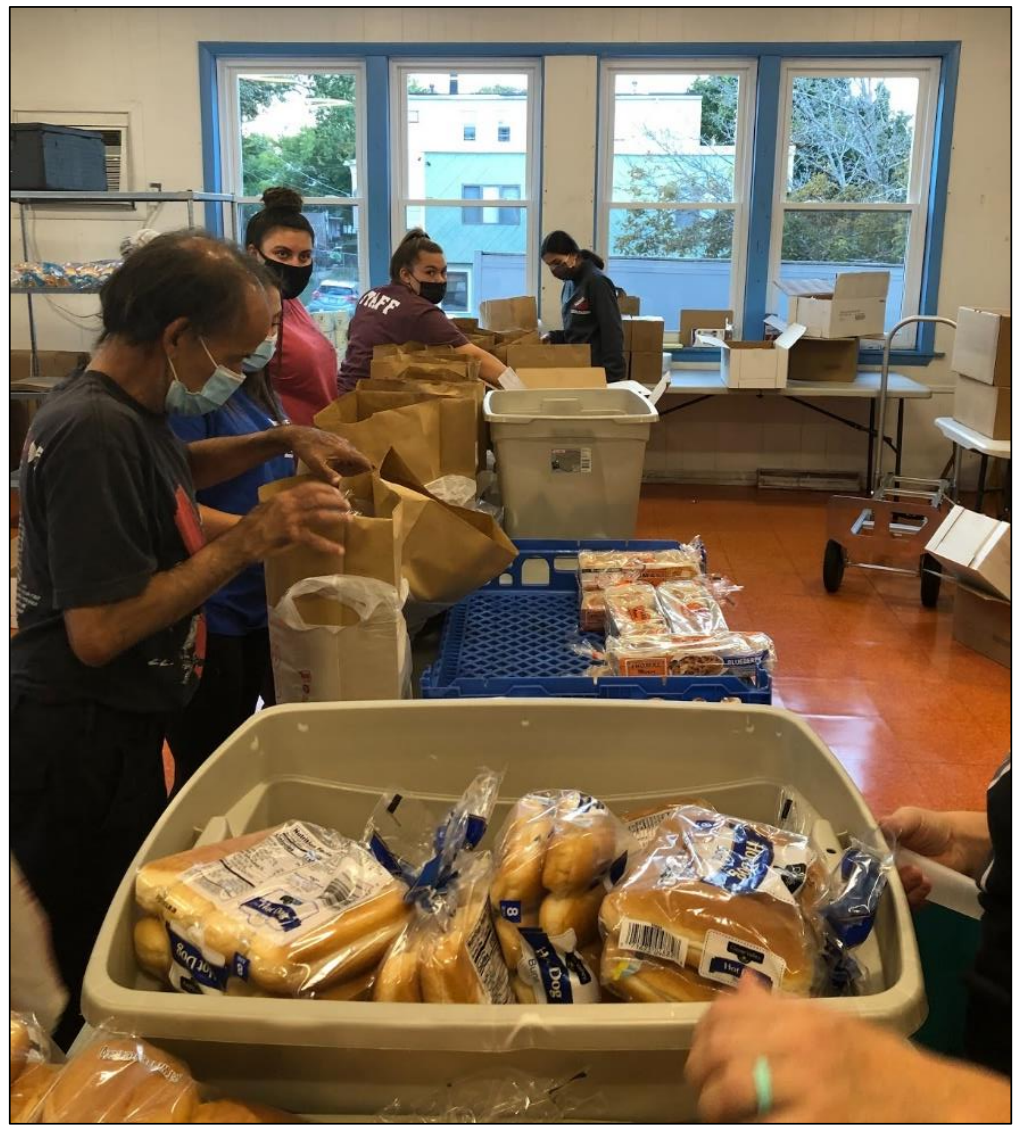

Photo courtesy of city of Revere, Mass. 
Figure 4. CHA Produce Market Expands to Meet Community Food Needs Throughout COVID-19

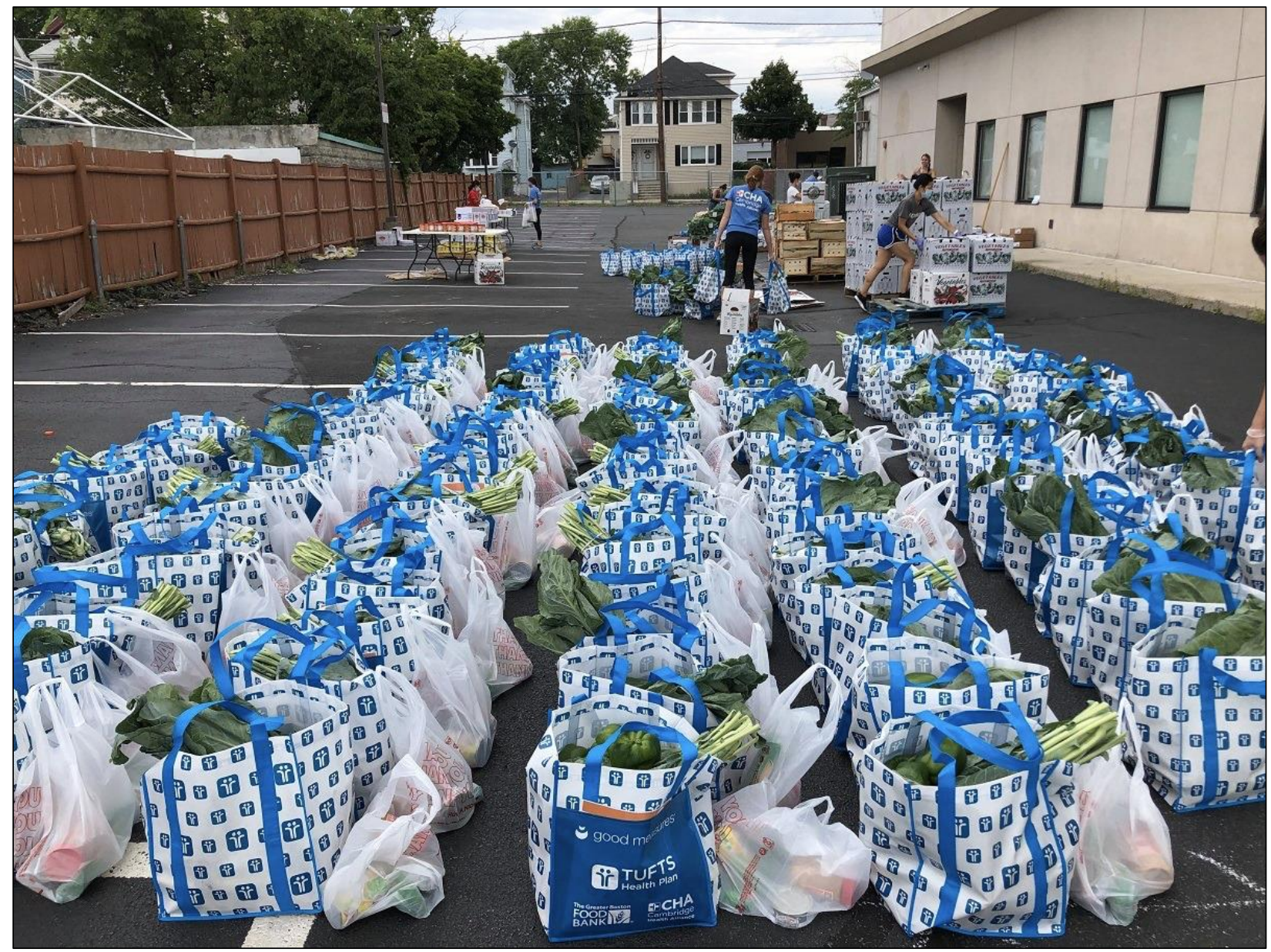

Photo by Jean Granick.

would talk about the importance of [wearing] masks outside. The Mayor's Office would talk about the science of masks. The Police

Department would talk about enforcement of wearing masks. The Department of Public Works would talk about the cleanup of masks. We would attack the issue from all sides.

Overall, we're noticing other people are reading what we're doing, and more people are connected to the city than ever before.

Molly: What advice do you have for others organizing food responses during this time?

Charlie: First, research best practices from other communities as much as possible. Also, be flexible: my city and my union allowed me to repurpose myself. The government can be very black and white, and this is an emergency situation where you need to be able to go into a gray area and do what you need to do.

My recommendation to anyone in emergency operations is: Become best friends with your school department. The school system has an incredible reach, no matter where you are. Also, involve all of your departments-not only police, fire, public works, and the mayor's office, but also the library and parks and rec. Each city department has their own constituency that they can reach.

Dimple: Your network and relationships are really important. The work of my department, Healthy Community Initiatives, has been focused on healthy eating and active living, and we had already 
built all of these relationships. We knew where to go and people knew who to come to. Even with the food pantry-we had a long-standing relationship with the church and the volunteer who runs the food pantry. Building that trust over the years enabled them to feel comfortable moving locations.

Molly: Do you think that the newly developed COVID-19-related programs will have a lasting effect on food insecurity in Revere?

Dimple: That's part of the work that we were doing, even pre-COVID: developing Revere's food economy. We're definitely learning a lot of things with COVID about hunger relief and food security, and how that ties in with the policy changes that we've been working on, such as the farmers market incentive programs. Prior to COVID, the farmers market had been our anchor around small food business development and helping immigrant informal food businesses become formal food businesses and entrepreneurs. That's all tied in with economic mobility, workforce development, small business development, and part of the antidisplacement plan for the city. And so, we really want to keep away from the band-aid approach. We want to look at the policies and systems and the environment and really change things.

Molly: Do you think there will be a long-term effect of having hundreds of residents volunteering?

Ralph: We're trying to bring the community together. Trying to unite it. So that's what we're hoping will happen with all these volunteers. People are meeting people that they probably would have never known. They're helping people in the community, and they're meeting people from different backgrounds.

The Cambridge Health Alliance continues to value, sustain, and grow relationships to address food insecurity. With our passionately local outlook, we believe that partnerships are critical to the bealth of our community. 